proved that the absorption in plants thus dried does not increase in proportion to their dryness; in fact, one of these plants which had lost a third of its weight by evaporation, absorbed much less than another which had only lost a tenth. Notwithstanding its greater dryness, the absorption was less, although the plant had not been dried so as to alter its texture. Evaporation or transpiration through the leaves is not, then, the cause of the ascent of the liquid in the trunk of a plant plunged in water, or, what is the same thing, it is not a vacuum in the superficial cells which occasions the ascent of the sap. This last does not take place unless there be a certain quantity of water in the vegetable tissue, which, perhaps, acts by adhesion upon the fresh water which is to rise, as a sponge is more rapidly soaked with water when it is damp than when it is dry. Dutrochet also tried to dry a plant, to make it reabsorb the water last, and to plunge it afresh in the water: he saw that the ascent did not take place unless the plant had regained the state of turgescence natural to it. This turgescence of the cells of the leaves is caused, according to Dutrochet, by the action of endosmose, by which the liquid would be transpired by the leaves in an active manner, and very different to that of a liquid evaporated in air. I may lastly state that Dutrochet has shown that the influence of light upon the ascent of the sap in vegetables is exercised in re. spiration, and in the fixation of oxygen in the vegetable tissues.

The phenomenon of the ascent of liquids in vegetables is, therefore, not owing to capillarity and imbibition alone: the cause is principally to be found in the roots, and partly in the leaves. It is probable that an action of endosmose takes place in the extremity of the roots; and it is not foreign to suppose, also, that a similar cause produces the movement of the chyle and lymph in the Iymphatic and lacteal vessels -a movement which we know is continued some time after death.

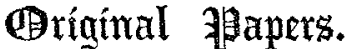

\section{NOTE ON THE \\ INVERSE RATIO BETWEEN DYNAMICS AND STIMULI IN THE ANIMAL ECONOMY.}

Bx MARSHALL HALL, M.D., F.R.S.

ThERE is no more interesting view of living nature than that which sets forth the reciprocity between the influence of the animal and vegetable worlds on the atmospheric air; whilst animals appropriate its oxygen, and return an equal bulk of carbonic acid, vegetables absorb the latter, appropriate its carbon, and give out oxygen.

There is a reciprocity between these two worlds of another kind: the other excretions of animals become the food of vegetables, whilst these vegetables themselves are the food of a certain class of animals.

It is on this account that fish and water-plants, placed in the same water, provide, as it were, for each other.

Wishing to investigate this matter, I placed some tadpoles in a limited portion of water, in which $I$ also placed some slender water-plants. At length these plants were entirely deprived of their small leaves by these voracious little animals. From that moment they ceased to grow and to undergo their transformation into the batrachian form!

This fact is interesting as denoting the influence of food on growth and development.

But another observation, of great interest to the physiologist, was made: the tadpoles remained in the most lively state in the water, as long as they retained their tadpole state; but from the epoch of their transformation into the batrachian form, they became, if retained in the water, affected with asphyxia, and infallibly died within a day or two.

Passing from the fish state, or the condition of waterbreathers, to the batrachian state, or the condition of airbreathers, they became asphyxiated if they remained in the former element. Doubtless, the former condition consists in a higher degree of vital dynamics-the excitability of the nervous, and irritability of the muscular systems; and a lower degree of stimulus-food and respiration: whilst the latter consists in a lower degree of dynamics, and higher degree of stimulus. The tadpole is not only a water-breather, but it is herbivorous; the batrachian is not only an air-breather, but it is insectivorous.

It is not my intention to prosecute this interesting view at present; but $I$ thought it might suggest an important topic of investigation to some professional brother if I placed these facts on record.
There is another fact, of no less interesting kind, bearing upon the same THEORY; for, though long neglected, a theory, and a beautiful theory it is-and perhaps the most general in regard to animal nature we possess.

Frogs taken from their cold bed of mud, in the month of March, are found to be endowed with the most extraordinary degree of excitability of the nervous system and irritability of the muscular system. Caught in the fields in the warm month of June, this excitability and irritability are found to have diminished in an equally extraordinary degree;-so that experiments on these properties, which succeeded admirably in the former season, are far less marked in the latter.

In March, these batrachia are reduced to the lowest degree of respiration, of food, and of temperature; their dynamic properties are therefore at the highest. In June, they breathe and feed highly, and have a proportionately elevated temperature, but a lower degree of excitability and irritability.

There is an inverse ratio between the dynumics and stimuli in the animal kingdom and economy.

This LAw, though set forth many years ago, has hitherto excited little attention-a proof, in opposition to a general remark, that truth, and truth of the most deeply interesting character, will not make its own way. It even requires, for its adoption, to be stated again and again, and so stated as to compel attention, and adoption, and application.

Of the last, I may present my readers with some beautiful specimens on some future day. These are not limited to mere animal physiology, but have their place in human physiology and pathology.

Sleep and infancy are periods of low respiration and other stimulus; and the occurrence of convulsive affections at this tender age, and during the operation of " tired Nature's sweet restorer," attests the high degree of excitability of the nervous system.

But I cannot now pursue this subject, Only, in conclusion, I would just remark, how carefully nature has protected the susceptible foetus in utero; and may I not add, how incautiously we have all, in testing the existence of a foetus, or of life in the foetus, applied our hand, taken fresh out of cold water, or sudden pressure, or succussion, over the region of the impregnated uterus. May not this, and similar acts, or accidents, have been the unsuspected cause of some congenital nervous affections, as podismus (club-foot) ?

On the other hand, if we want a remedy against undue excitability, we can have recourse to no more efficacious means than augmented respiration - that is, "air and exercise," which will tend to quicken digestion, and the consequent augmented quantity of food.

On this principle " training" proceeds. It is the highest kind of life which the human subject can live, physically speaking, and cannot be maintained for any considerable space of time. This high health leads to exhaustion of the vital powers-just as an animal dies in an atmosphere of oxygen,-just as a bat, taken from its state of hybernation, dies, if made to fly about; and just as patients, in a state of inanition, or of asphyxia, are killed by too much stimulusfood, wine, or heat. Extremes cannot be long borne, and transitions must be gradual and slow, which may be said of transitions from high to low, as well as from low to high. If an animal be placed in a limited portion of atmospheric air, until it begins to show distress, however it may appear to be well when removed into the atmospheric air, frequently dies of a secondary asphyxia shortly afterwards.

June, 1847.

ON THE

\section{CONTRACTIONS OF THE UTERUS.}

\section{Bx WILLIAM FREDERICK BARLOW, Esq., M.R.C.S.E.}

There can scarcely be a more interesting and important inquiry to the physiologist than the nature of uterine contraction, and certainly it requires further investigation. Perhaps I may be permitted to state some of the most prominent facts which bear upon it, and dwell shortly upon the conclusions to which they seem to lead.

No difference of opinion would appear to exist as to the influence of the brain upon it, and it is clear, that when the functions of this organ are suspended or abolished, laboux can be begun and completed. Not that the brain has no concern in the process, but only that it is not essential to it. It assists it voluntarily, by contractions, which, though not uterine, materially aid it at a certain stage, and acts upon it by the different emotions for good or ill.

What is the relation between the action of the uterus and 
the spinal cord? Is the presence of the latter, or of that part of it with which the uterus is connected, necessary to parturition?

Experiments and cases unite in testifying to the power of the cord as respects the uterus. They show it wilh a force which nothing yet said of the influence of the sympathetic nerve over this organ seems at all to lessen. In coma there is parturition; in paraplegia there is parturition, if the source of it be such as not to separate the uterus from the cord; but there is no case to show that labour can take place unaided, if the cause of paralysis abstract the uterus from all relation with the spinal marrow.

I have read carefully the recent paper of Mr. Snow Beck.* His inference as to the independence of parturition on the spinal cord, founded on phenomena observed through the administration of the vapour of ether, is, in my humble judgment, anything but conclusive. He fails altogether to show that the act of parturition can be performed as well without spinal influence as where this is present $\mathrm{It}$, seems no unfair construction of his observations to suppose that such influence $i s$ present where he thinks it is not. Neither are his remarks consistent with themselves, as $I$ am sure a comparison of two passages, which are both used to enforce precisely the same point, will make plain to himself. He says, "In many of the recent cases in which the inhaling of ether has been employed to relieve the pain of operations in mid wifery, the whole of the functions of the brain and spinal cord, including the reflex functions, have been annihilated for a time, and yet the action of the uterus went on as regularly, as vigorously, as if all the functions of the nervous system were in full foree." Mr. Beck then brings forward phenomena to illustrate this opinion, and proceeds materially to diminish, if not quite destroy, its force, by adđing, "In a word, all the most obvions reflex actions are in abeyance;" which phrase, most vague and indefinite compared with his former one, and certainly not nearly so favourable to his conclusions, he repeats. Not all, then, but the most obvious reflex functions are, according to Mr. Beck, held in abeyance, though his authority might be quoted for the "whole" of them being so, were the passage selected in which that word occurs.

Again, when Mr. Beck spealss of " the most obvious" reflex functions, he omits to mention the act of respiration. Yet this is the chief of them all. This surely cannot be so long suspended as to enable us to determine that parturition can be completed with as much regularity and energy without all the reflex functions as with them. Fther often affects the brain only partially, and it may in like manner only partially act upon the spinal marrow, suspending some of its actions, whilst others remain.

M. Serres long ago performed sone experiments from which it may be inferred that the activity of the spinal cord has greatly to do with uterine contractions. $\neq$

1. He found that when he divided the spinal marrow of pregnant animals, (rabbits, guinea-pigs, \&c.,) in the lumbar region, some time before the period of parturition, they died without being delivered. It is of importance to know how long the experiments were made before the expected close of gestation-how long the animals lived after the injury of the cord-and what was their condition between the time of its infliction and their death. Animals so treated may die quickly from the effects of shock and other consequences of the injury, and no true conclusions can then, of course, be drawn.

2. II ascertained that the like experiments made during labour effectually arrested it.

3. He has shown, that by irritating the spinal marrow in the lumbar region, uterine action and abortion may be excited. And here, as it is hardly necessary to add, the uterus is affected just as the voluntary muscles may be affected, either by irritation of the spinal cord, or the trunks of their appropriate nerves, obediently to the law of Haller. Is there a single instance in which a muscle, so influenced by such irritation of the spinal cord after death, receives, notwithstanding, no motor power from or through it during life? Does not the experiment declare plainly enough that motor nerves proceed from the cord to the uterus? And if so, are we to hold those motor nerves superfluous, on the ground that the "sympathetic system" is of itself able to to effect parturition?

4. M. Serres has made a most instructive remark relative to the influence of strychmia on the uterus. He has discovered, that when injected into the veins, it affects the organ,

* On the Structure and Functions of the Sympathetic Nervous System, as distinct from, and independent of, the Cerebro-spinal system. By T. Snow Beck, M.R.C.S. See Tez LANCET, June 12th, and "Medical Gazette" of the same date.

$\dagger$ Anatomie Comparée du Cerveau, tome ii. p. 610 . even as the latter is excited by mechanical irritation of the. cord. On the supposition, that the cord furnishes the uterus with motor power, the result of this experiment might have been foreseen, and very likely was anticipated, by M. Serres. Wherever the influence of the cord extends, there strychnia operates. But is there any experiment to show that it possesses power over the sympathetic nerve?

From this effect of strychnia upon the uterus, M. Serres concludes, that there is fear of this medicine producing abortion, if administered as a remedy for paraplegia, occurring during the time of pregnancy.

$I$ will now pass from these experiments to two cases of paraplegia in pregnant women, related by ollivier and Brachet, which have excited no little notice, and have an im. mediate relation to the subject.* In the one, labour was effected without aid ; in the other, instruments were required.

First, as to that of M. Ollivier. It is entitled " Pregnancy; paralysis of the motion and sensation of the inferior extremities; spontaneous, painless labour; death the tenth day afterwards; hydatids external to the spinal dura mater, and compressing the cord." Here is given an outline of the case, and the source of its symptoms. The latter could not indicate their exact origin: it was clear that the cord was compressed, but no one could have discovered by what it was so. Two points mainly concern us here: Was the labour performed well and quickly, or the contrary? What was the spot of compression? In answer to the first question, one extract will suffice. "The labour was completed suddenly, and with so little pain, that the woman was only made conscious of it by the emptying of the abdomen and the cries of the child."

The remaining inquiry is of great moment. If the lesion had been foumd of such a kind, and so situated as to preclude the idea of the spinal cord having aught to do with the completion of the labour, there would have at least been recorded one case to show, that parturition can be accomplished without any assistance from the spinal marrow. But in this remarkable instance the cord was compressed remotely from the nerves it distributes to the uterus. There was a cyst in the thorax which contained hydatids. "The right lateral hole of the fourth vertebra, which gives passage to one of the dorsal nerves, was entirely open; its diameter was large enough to admit the extremity of a finger, and it led into the spinal canal. It appeared to us, then, that some of the hydatids contained in the cyst of the thorax had entered, through this opening, the vertebral canal. To leave no doubt upon this point, we opened the spine to a great extent, and found there a dozen of hydatids of varying sizes, which extended upwards from the inter-vertebral opening to the top of the first dorsal vertebra; there they were accumulated, attached to the external aspect of the dura mater, and embraced it circularly as a ring; in this spot the membrane was thickened, compact; its colour was reddish, its capillary vessels were congested, and it formed a sort of collar which compressed the spinal marrow." There was no morbid change noticed in the cord; it had suffered from compression only; its consistence was normal. Professor Chaussier observed, in some comments upon the case, that " the insensibility and paralysis of the inferior extremities supervened, when the hydatids, after having passed through the hole of the fourth dorsal vertebra, compressed, by their number and their volume, the spinal cord."

The case of M. Brachet has most different features.f It has been recently brought forward by Mr. Beck. Unfortunately, there seems no record of the seat of paralysis; but that it was very low in the cord might be inferred from the phrase, - " the loss of sensation was complete as high as above the pubis." I suppose the cord to have been involved where motor nerves are given to the uterus, and the case to exhibit the effects of the abstraction of the influence of the cord upon the act of parturition, and thus the incompetency of the uterus to expel its contents is to be accounted for. In expressing this view, I agree in the opinion already given upon the matter by Dr. Marshall Hall. But Mr. Beck, "granting the supposition to be correct," (as he has said,) cbserves, that there is no evidence to show that " the action of the uterus was slow, feeble, imperfect, and incapable of expelling the child." Let us examine the phenomena. When M. Brachet first made his examination, " the orifice of the uterus was open, and of remarkable softness." "He left parturition to Nature for twenty-four hours, yet it did not progress. The lady had been quick in her former confine-

* Traité de la Moelle Epinière, Deuxième Edition, p. 784 p. 266.3 
ments, and wished to have this finished, from the feeling that she would not be able to complete it without assistance. By some titillations of the neck of the uterus, he tried to provoke contraction, but without effect; the soft organ admitted of being so much distended in every direction, that the orifice was completely dilated. The head of the child presented naturally."

I think most obstetrical practitioners will agree that this state of the orifice of the uterus was one which would promise a quick delivery under ordinary circumstances. I should not have expected much delay, especially if to this condition of parts were to be added, "rupture of the membranes." These were ruptured by M. Brachet. "Water escaped by the contraction of the uterus; the head descended, and engaged in the superior aperture of the pelvis, but did not move." For two hours it was attempted to excite contraction in various ways, but vainly. At length the forceps were used, and the child extracted. The placenta was not expelled, though "frequent friction of the abdomen was resorted to for more than an hour :" and when it was eventually extracted by the hand, the uterus contracted with an extreme degree of slowness. And all this happened in the case of a lady who had experienced already three confinements, which were "very quick." Might it not fairly be concluded from the irritation of the nterus and the friction of the abdomen, both alike failing to produce contractions, that no reflex actions could be excited in this case, as in general they can be? There was some contraction, it is true, just enough to be noted and to disappoint. Nothing more need be said; for I do not contend that the spinal cord is the sole source of the contractility of the uterus, but only that that portion of it which is connected with the organ would appear necessary to efficient or normal parturition. And this conclusion seems the more reasonable when the results of experiment are compared carefully with what pathology has informed us of.*

M. Brachet attributes the state of the uterus observed in this case, to the effects of the paralysis. M. Serres does the like. Dr. Tyler Smith has observed respecting it, in his remarks on parturition,- "In paraplegia from disease involving the lower portion of the spinal marrow, labour either does not take place, or proceeds with extreme inertia, as in the case related by M. Brachet." M. Serres observes: "The integrity of the inferior part of the spinal marrow would appear necessary, in order that the uterus may rid itself of the product of conception. In two paraplegic women, arrived at the term of labour, the uterus remained so inert, that in the one, the ncck did not sufficiently dilate, in order to permit the introduction of the forceps; with the other, the infant was obliged to be extracted by the Cresarian section."

M. Ollivier, contrasting his own case in which the laboux was energetically accomplished, with that of $\mathrm{M}$. Brachet, in which it was efferted by instruments and not the uterus, suggests, that "the destruction of the tissue of the spinal cord is, perhaps, a necessary condition to the coëxistence of paraplegia and inertia of the uterus," seeing that, in the instance which he has himself related, that there was simple compression of the cord merely. But the question for consideration would seem to be, not how, but where, the spinal cord is affected, in reference to the performance or failure of parturition. Had the reflex function been known to this observer at the time of his making this remark, the difficulty which naturally struck him would have been lessened, if not altogether removed. If the seat of paraplegia be above the origin of that nervous supply which is received by the uterus from the spinal cord, there is nothing necessarily to impair its action, if it be dependent on the reflex function; for in this case, as Dr. Marshall Hall has pointed out, its incident and motor nerves and the arc connecting them, would be perfect still; but if the seat of lesion involve that arc, the result is different, and the case of M. Brachet is, very probably, an instance of the consequences to parturition which follow the abstraction of spinal infuence.

I cannot but conclude that much more precise deductions may be drawn from the experiments and cases which have been referred to, than from the effects of ether, as described by $\mathrm{Mr}$. Beck. Let any physiologist carefully read over the remarks of that gentleman, and then ask himself-Is it slown that labour goes on "as regularly, as vigorously," without the reflex functions, as with them? I have had the advantage of seeing severe operations performed on patients under the influence of ether, by $\mathbf{M r}$. Lawrence, $\mathbf{M r}$. Stanley, and $\mathbf{M r}$. Lloyd in the operating theatre of 'St. Bartholomew's Hospital, in which pain was indubitably and admirably prevented.
Supposing that the reflex functions were altogether suspended in any of those cases, they most certainly ceased not for that length of time which would enable us to determine that the action of the uterus is altogether independent of the spinal cord. But in the instances I refer to, the cerebral functions appeared in abeyance, whilst those of the cord continued, at least in part; respiration remained, remained even where there was excessive relaxation of the voluntary muscles. It is enough, surely, to abolish sensation and volition, without going further. The effect to aim at is that effect which the least interferes with the vital functions, provided it suffice to annul sensibility. Nor is it so light a thing to suspend the respiration; for if this cease, and the heart's action yet continue, there is obviously danger of asphyxia, should the suspension be persevered in. How long can respiration be quiescent in such a case without risk of life? At any rate, there is need of observance and care.

Mr. Beck has made reference to the observations of Professors Dubois and Simpson, but the passages he has quoted do not sustain his opinions. They fail to demonstrate that the act of parturition can be effected as well without the spinal cord as with it. Professor Simpson, indeed, in the extract given, speaks of apathy and insensibility, and shows that labour can be effected independently of the brain; but if the reader will turn to the passage, he will not find one single syllable as regards the reflex function of the cord?

I do not venture to say that the sympathetic nerve has nothing to do with the contractile power of the uterus. This nerve has probably a certain action, if not such action as would effect labour independent of the cord. Its contractions may be of a double or mixed character, as are those of the cesophagus, of which Dr. Marshall Hall has observed, "The fact is, I believe, judging from my own experiments, that the action of the cesophagus in deglutitions is of a double or mixed character; prompt under the influence of the pneumogast ric nerves, and of a slower character under the peristaltic action of its muscular fibres."

But to view the question in another light. I cannot but advert to the remarkable analogy between the contraction of the uterus and reflex acts in general. Let it be compared with respiration, so far as muscular action is concerned; emotion influences, volition helps them both. In one great respect parturition altogether differs from respiration. It is a periodical act. It may be performed or the contrary, being provided for, dependent on a peculiar state, which may or may not happen. The period at which it is wont to occur cannot be explained by anything we know, though we perceive the purpose that is gained by it. Specially and wonderfully adapted to its end, the organ of parturition bides its time, until the being to be born can live independently of her who is to bear it, and so it waits according to a law most definite, and framed in all wisdom. But respiration is continual, for its being so is necessary to life. So much for this contrast. Let us now note a fow striking resemblances between parturition and respiration, which are apparent in the means whereby they are occasionally, provisionally excited. They are seen chiefly where the foetus fails to provoke the one, and the pneumogas tric ceases to excite the other. I cannot go fully into this important matter, and can only treat it cursorily. The contractions of labour may be produced by stimuli, when they cease to be occasioned normally; so may the movements of respiration. Both kinds of motion obey physical stimuli, and both acknow. ledge the effects of temperature. Both also may be excited by irritation affecting parts distant from the seat of action. By friction we may excite respiration, and once I produced the most active inspirations in a nearly asphyxiated infant by tickling the palm of the hand. In this case, how distant was the seat of irritation from the nerves and muscles necessary to breathing! The uterus is in like manner susceptible of remote stimuli. The drinking of hot and cold fluids seems thus to act.

At present we know not the different ways in which parturition may be excited remotely and reflexly. In cases of coma, may it not be occasioned, as respiration may, by the excitor nerves of the spinal marrow, far more varionsly and widely than is yet supposed. A very singular case of parturition during a state of complete insensibility is detailed by the illustrious Harvey.* Labour would appear to have been brought to a close by irritation of the fifth pair of nerves. That convulsive movements were thus produced is certain, during which the uterus would seem also to have acted; for it is expressly said that then the "labour advanced." Whatever may be the view taken of the case, it is so interesting

* See Works of Harvey, edition of the Sydenham Society, p. 534. 
that I will proceed to quote it. "I am acquainted," says Harvey, "with a young woman, who during labour fell into so profound a state of coma that no remedies had power to rouse her, nor was she, in fact, able to swallow. When called to her, finding that injections and other ordinary remedies had been employed in vain, I dipped a feather in a powerful stimulatory, and passed it up the nostrils. Although the stupor was so profound that she could not sneeze or be roused in any way, the effect was to excite convulsions throughout the body, beginning at the shoulders, and gradually descending to the lower extremities. As often as I employed the stimulus the labour advanced, until at last a strong and healthy child was born without the consciousness of the mother, who still remained in a state of coma." In the belief that at the time the convulsions were produced, the uterus was excited also, I think that it was possibly aroused to action in a reflex manner by the excitement of the fifth nerve indirectly acting on it through the spinal cord.

That it may be called into action, just as the respiratory muscles may, by cold applied to the cutaneous surface, has been long admitted. Cold, thus applied, has saved life often by contracting it in flooding; and thus used, $I$ have known it very effective in expelling the placenta. And as in many cases of suspended breathing, cold and heat are most efficacious when used alternately,--for to surfaces of their own degree of temperature they are no excitants at all,--so, in like manner, when parturition lingers, they may accomplish by turns what neither could effect by itself. This fact has been most interestingly shown by Mr. Simpson, who was the first, I believe, to use this method of applying temperature in the case of labour. He says, "the cold water applied suddenly to the abdomen, was most effective in producing uterine contractions. After a little while, however, this lost its utility. The abdominal surface becoming cold from the repeated application, the water no longer acted as an excitant. Accordingly, warm flannels were applied, to restore the temperature, and then cold water was again applied, with decided effect.".* Since the publication of this case, I have once had occasion to recommend temperature, where labour so lingered that it was feared instruments would at length be required, with satisfactory result. The other day I found a case in which cold had been used to produce delivery, and, as it would seem, not vainly. It is detailed in a letter of Dr. Pearce to Dr. Lettsom. "A woman, whom a midwife could not deliver, had cloths dipped in cold water laid upon the abdomen; as much cool air as possible was admitted; and everything she took given cold; in consequence of which, she was soon delivered of a large still-born child."

Inasmuch as cold has been long known to produce uterine action after the birth of the child, it is curious that it has not been used more frequently, with the view of exciting it before the birth is completed. Temperature could be used where the ergot would be utterly inadmissible, and I think it capable of a far more extended application than it has yet received, and the more especially, if it be used as Mr. Simpson employed it. Cold is every day persisted in, even in states of exhaustion, where it should be changed for warmth, at least for awhile.

The similarity between the action of temperature on the respiratory and parturient actions is very palpable; does it not operate, in both cases, through the same principle, and excite the reflex function of the spinal cord?

Lastly, let me observe, that the question before us simply is-What is the influence of the brain, what of the spinal cord, what of the sympathetic nerve, as respects parturition? First, if it be possible, let their separate effect, afterwards their combined powers, be determined. That the brain is not necessary, we know; but that it acts as an auxiliary, we know just as well. Let the inquiry be analytically and synthetically pursued, and as calmly as though it had never been discussed, pursued simply as a matter, not between this and the other physiologist, but between truth and error.

As to the share the sympathetic has in it, let it be well explored and discovered, if it can be; but let us be careful not so to comment on the office of this nerve as to provoke a repetition of the phrase of Müller-that pointed, called-for phrase, - " it explains everything, and yet nothing;" called for, because so many conclusions that have been hastened to, concerning it have proved to be fallacies- 'cecidere cadentque.'

At present, we must confess how much is to be learned re-

* See The La veet for December, 1842, p. 437, and Dr. Marshall Hall's "New Memoir on the Nervous System," p. 85. I have endeavoured to insist upon this mode of alternation, with which temperature is effective, where without it, it would fail, in a short paper, to which I may here refer, in ThE LANCET, May 13th, 1843 . specting parturition, ere we can explain many of its phenomena. As it is, to what a variety of queries must the candid physiologist at once reply, "I do not know"-words which should never be difficult of utterance to any one who feels that the confession of ignorance is a step to its removal, and who is a sincere inquirer after truth."

\section{CASE OF \\ AN ENCYSTED TUMOUR ON THE RIGHT SIDE OF THE NECK.}

By CHARLES MAYO, Esq., F.R.C.S.E.

SENIOR SURGEON TO THE WINCHESTER COUNTY HOSPITAL.

Francrs M-, aged twenty-nine, came into the County Hospital, from Andover, on the 17th of March last. He had an oblong semi-elastic tumour in the right side of the neck, extending from the angle of the lower jaw to the clavicle, and filling the space between the sterno-cleido-mastoideus muscle and the trachea. During the act of deglutition, the tumour was raised, and sunk or depressed, in accordance with the motions of the larynx and root of the tongue, and could be made tight, by holding the breath. An evident fluctuation could be felt, by passing the finger into the bottom of the mouth, under the tongue, and making a counter-pressure on the tumour externally; and it appeared that, eleven years ago, a puncture had been made into the swelling under the tongue, by Mr. Westlake, of Andover, and a teacupful of albuminous fluid evacuated thereby. Since that time, it had gradually refilled and extended, and although not very painful, had become so cumbersome as to make him desirous to have it removed by an operation. The tumour would bear handling without pain, and might be grasped and drawn outwards, so as to show its independence of the surrounding structures; it was rather too soft for a fatty tumour, and more like the consistence of steatoma.

From March 18th to April 1st, his general health was attended to, and various local applications used, without benefit; among these were lotions of zinc, spirits of wine, iodine ointment, \&c. But on this day, having been brought into the operating theatre, I first punctured the centre of the swelling with a small trochar, through which, about a table. spoonful of serous fluid escaped, but without sensibly diminishing the bulk of the tumour. I then divided the skin, which was quite loose upon it, to the extent of four or five inches, and dissecting it back on each side, came upon the platysma-myoides muscle, closely investing the parietes, or cyst of the tumour; a small portion of the cyst, however, could be perceived at the outer edge of the platysma, and 1 tried, with the handle of the scalpel, to detach it from the muscle and the subjacent structures, but finding that the sac extended so deeply into the hollow containing so many important vessels and nerves, I resolved not to attempt any further detachments in that direction, but to make a free opening, and take away as much of the anterior part of the cyst as possible. The incision into the cyst was followed by about half a teacupful of white fluid, and a pint bleeding dishful of greyish substance, of the consistence of fresh mortar, which I dug out, as it were, with the handle of the knife. In detaching a portion of the sac, with the muscle covering it, a considerable artery was divided, near the basis of the jaw, which gave us some trouble to secure, and at the lower part of the wound, two or three branches of the superficial jugular veins were cut, and filled the bottom of the chasm several times before we could secure them. With a view to restrain further hæmorrhage, the wound was filled with portions of lint, dipped in oil of turpentine; cold cloths were applied externally, and the patient put to bed, with the head and shoulders raised by pillows; he was ordered to have lemonade and cooling drinks, and to be kept quiet. In the evening, I found that considerable oozing had taken place, and I removed the cloths, and applied fresh ones, dipped in weak zinc lotion; as he complained of sore throat, and the respiration was rather obstructed, saline effervescing dranghts were ordered every four hours.

April 2nd.-The pulse had rallied; the discharge from the wound had been profuse, chiefly serous; the throat more swollen; and deglutition difficult; I removed the lint soaked in oil of turpentine, and substituted other portions of lint, dipped in solution of sulphate of zinc, strong enough to

* Cuvier beautifully says, in his elcquent eulogy on Joseph Priestley, "Nothing was easier for him than to say these words, "I do not know, which cost the greater part of the learned by profession so much to pronounce." -Efoges Historiques, tom. $i$. 